Article

\title{
Scanning for Cultural Competency in Online Urban Planning Programs
}

\author{
Brian Garcia \\ Urban and Regional Planning, California State Polytechnic University Pomona, USA; E-Mail: bpgarcia@cpp.edu
}

Submitted: 31 May 2021 | Accepted: 5 August 2021 | Published: 17 November 2021

\begin{abstract}
This article investigates online urban planning degree programs. The Covid-19 pandemic forced urban planning programs to pivot to online delivery instantly. However, there is little preexisting knowledge on online learning in place-making fields of study both in the literature and in practice. Meanwhile, working and learning from home is expected to continue as part of urban planning education and practice. The key tension of teaching urban planning online, as a traditional place-dependent field, is the starting point for our inquiry in this article. To understand the state of online urban planning programs, an internet search was conducted. A database of 176 higher education programs was created that identified only eight online programs including degree-granting and certificate programs in urban planning. These urban planning program results were concentrated in the western United States. Key challenges in online learning were identified through a literature review, including pedagogical efforts in skill transfer and multiculturalism. The eight-program curriculum strategies were analyzed through a qualitative case study analysis. A discussion on the tactics during the transition from in-person to online education in the Department of Urban and Regional Planning at California State Polytechnic University Pomona is also presented. This article provides online urban planning program information for educators currently teaching online and for those interested in creating an online program. Online programs in place-specific fields such as urban planning have particular challenges in understanding communities without site visits, ethnography, or robust in-person community engagement. Online urban planning programs must make additional efforts to achieve a social, collaborative learning and practice environment.
\end{abstract}

\section{Keywords}

online degrees; online teaching; online urban planning classes; urban planning education

\section{Issue}

This article is part of the issue "Towards Digital Urban Regeneration: Embedding Digital Technologies Into Urban Renewal Processes and Development" edited by Dalit Shach-Pinsly (Technion-Israel Institute of Technology, Israel).

(C) 2021 by the author; licensee Cogitatio (Lisbon, Portugal). This article is licensed under a Creative Commons Attribution 4.0 International License (CC BY).

\section{Introduction}

Urban planning is inherently about the built environment and has largely been discussed, analyzed, and practiced in an effort to adapt physical space to our needs and enjoyment. Place has long been at the center of urban planning and regeneration work, including the fixed economic and social aggregates that constitute the city (Teitz, 2007). Urban planning professionals work to understand the patterns, growth, and change of the city and to respond with effective urban planning solutions (Teitz, 2007). However, Covid-19 has forced all disciplines into online teaching and practice, including the placemaking field of urban planning.
This article investigates online urban planning programs to understand their composition and how they address remote teaching and learning in a field based on place-making. After a search for and creation of a database of urban planning programs worldwide, few online programs were in urban planning were found. This article presents three themes of inquiry that were developed from a literature review and scanned for in the curriculum of online urban planning programs including place-based project learning, skills transfer, and cultural competency to work within an online milieu ethically. A search of online programs in urban planning found one bachelor's program, three graduate certificate programs, and four master's programs in urban 
planning. The Master of Urban and Regional Planning at the University of Florida was the only accredited online program found.

Many urban planning programs have been forced to pivot to online education delivery due to Covid-19, but now plan to continue incorporating more online learning into their programs in the future. However, the small body of urban planning online programs to learn from is a challenge for educators. This article intends to contribute to the discussion about the increased number of online urban planning curricula by mapping the current provision of online urban planning programs and analyzing their curriculum for themes and courses on place-based project learning, computer skill classes, and classes that address ethics and cultural awareness in urban planning practice. After discussing those curriculum strategies, the case of the Department of Urban and Regional Planning at the California State Polytechnic University Pomona (Cal Poly Pomona) is presented to offer in-class strategies to teach essential skills and cultural competences online in order to be an effective place-based urban planner.

\section{The Tension Between Place and Dispersion in Urban Planning Education}

Fixed spatial elements of the built environment have been presented as a foundation of urban planning, including firm locations, economic clusters, economies connected by geographic region, and the overall polycentric urban form of contemporary cities (Hall, 1998; Pain, 2016; Reades, 2016). However, Hall wrote about other aspects of cities fundamental to urban planning education and practice, including transport and the movement of people and goods, as well as the creation of sociable cities and zones of hope. The key tension between the dispersed aspects of urban planning with place-specific components of urban planning is the theoretical starting point for this article.

Urban planning and urban regeneration are inherently inter- and multi-disciplinary, as illustrated in Le Play's place-work-family triad (lieu, travail, famille) and Geddes' dimensions of society, "place, work, and folk" (Batty \& Marshall, 2017). Geddes' basic components of society were key components of contemporary social science, geography, economics, and sociology. The basis for urban planning might similarly be place, economy, and people (Batty \& Marshall, 2017). Greater pluralism in planning versus large top-down planned projects would later be highlighted in the political efforts of Jacobs (1961). Ideas of place in urban planning were challenged by the world of the expanding automobile observed by Melvin Webber (Teitz, 2007). Webber's wellknown phrase community without propinquity questioned the concept of place as central to geographic and urban planning work. Webber observed that urban planners were focused on place but at this time there were visible examples of place becoming less relevant (Hall,
2007). However, since Webber's work on urban dispersion, we have also seen intense concentration including the rise of new financial districts in Shanghai, Mumbai, and Moscow, along with rising real estate prices in urban cores (Teitz, 2007).

Urban planning is largely situated within a geographic place, focusing on aesthetics, public spaces, parks, housing, and infrastructure including transport (Alpopi \& Manole, 2013). Urban planning solutions themselves involve a synthesis of built, transport, and social issues (Alpopi \& Manole, 2013). However, for a long-term sustainable solution, the community must be involved in the diagnosis of the challenge as well as in the formation and ongoing implementation of the solution (Alpopi \& Manole, 2013; Deakin \& Allwinkle, 2007). In placespecific fields, like urban planning, students commonly learn from real-world challenges and locations, to practice analytical and prescription skills to addressed urban challenges. A large part of the analysis and learning in these project courses comes from dialogue with local stakeholders and site visits. During the Covid-19 pandemic and in online learning, students were removed from their project sites and communities. Interaction and education were reduced to what was available online in the form of satellite imagery, literature, photos, or census data.

Educating future urban planners has always entailed the tensions of remote practice, place specifics, and local knowledge (Moore et al., 2015). In higher education, students often travel for university programs and then take their gained knowledge back to their city of origin or a third location to apply their planning knowledge (Moore et al., 2015). Yet, challenges and solutions in urban planning and regeneration are inherently place-based and many cite local knowledge and context-specific solutions as key to sustainable urban regeneration (Deakin \& Allwinkle, 2007; Moore et al., 2015). The responsibility of planning educators is to provide students with the skills to acquire local knowledge and invent solutions on their own. The increasing online or remote aspect of practice adds another complexity by distancing students from each other and their site community. Meanwhile, very little scholarly work has been done in urban planning on teaching and practicing remotely (Myers \& Kitsuse, 2000).

Surveys on the future of work and space show that $74 \%$ of surveyed companies plan to continue remote work of some kind after covid-19 abates ("Shifting some employees," 2020). Office vacancy rates in the United States are unsurprisingly up to $17 \%$, however, this trend of declining office space occupancy began before Covid-19 (Ryan, 2021). Average lease lengths have also been shrinking since the end of 2018 (Ryan, 2021). These results suggest that urban planning educators need to train students more strongly in online tools, software, and remote work communication for their future practice.

Distance, online, or remote education may be described as an education delivery approach that 
replaces face-to-face instruction (Godschalk \& Lacey, 2001). This article presents an investigation into online urban planning education programs organized by a faculty member to be delivered asynchronously, synchronously, or in a hybrid manner. Urban planning education in the United States has been dominated by three main phases, from the civic design and master planning era of the early 1900 s to the turn to the social sciences in the late 1940s, and more recently the attempt to understand multicultural and interdisciplinary complexity in urban planning (Dalton, 1989, 2001). A large part of the turn to understanding multicultural complexity and consciousness of ethnic and gender diversity came from students and their active role in their education (Dalton, 1989, 2001). Planning for the future must include an increased cultural competency, an understanding of ethics, responsibility, and a thorough addressment of community challenges in education and practice (Agyeman \& Erickson, 2012; Dalton, 1989, 2001). Historically, obstacles for increased distanced learning in urban planning have included the lack of compensation for course development and inadequate technical support (Godschalk \& Lacey, 2001). Three major themes or challenges have emerged for online urban planning education: (a) the importance of place-based project work; (b) the importance of computer skills to accumulate and analyze data; and (c) the need for a cultural competency within an online practice that is somehow able to empathize and connect with a project site community.

\section{Place-Based Learning in Urban Planning Education}

Problem-based learning is a key component of urban planning education (Shepherd \& Cosgrif, 1998). Problembased learning blends planning education and practice. Students work on a problem from life, earning skills and knowledge for their future practice as planners. The instructor sets up the problem and then guides the student through strategy and visualization. Problembased learning and urban planning practice are tied to an envisioned future (Freestone, 2012).

Ethnography is a research method in urban planning based on the premise that phenomena cannot be completely understood outside of its context (Salama, 2008). In urban planning, ethnography is used to understand cultural groups and the perceptions of people within their environment. Ethnography and action, or experiential research, cannot be duplicated by technology and this has implications for how data will be accumulated and how communities in need will be served and allocated resources.

\section{Technology and Skills Transfer in Online Urban Planning Education}

Distance or online education has evolved from correspondence courses by mail, to universities granting degrees for programs based on broadcasts and tele- conferencing to the more recent method of course delivery online relying on classes over video conferencing or recorded lectures and multimedia (Godschalk \& Lacey, 2001). Today, online learning programs rely on the internet and multimedia tools, including email, course web pages, and online discussion forums. Students can present their work and discuss it with their colleagues and professors through video conferencing. Yin (2010) states that technological advances are permitting visually detailed, performance-modeled, and geo-referenced representations of urban environments. Computer models provide information on space, communities, energy, and these technologies provide opportunities for communication, collaboration, and understanding (Yin, 2010). However, Yin also states some challenges in GIS education, e.g., that photorealistic models must rely on some data from fieldwork, that students need to stay current on latest technology, and that modeling programs are expensive for planning schools.

Godschalk and Lacey (2001) present a case study and survey data from an introductory planning course at the University of North Carolina. They note several exchange programs and international course initiatives at the University of North Carolina that developed from advances in online instructional tools, user-friendly software packages, training opportunities, and support staff. With information technology, universities can compete for students abroad. Sufficient space at universities can be a challenge due to growing student populations and demand for education. Offsetting some in-person courses with online sessions or courses may alleviate some demands on physical facilities. Online learning also helps meet the needs of employed students, military students, and those that live far away from campus. However, many faculty members are concerned about a decline in the quality and efficacy of education without face-to-face opportunities.

Godschalk and Lacey (2001) also note the importance of a technology instruction center to support faculty and students that teaches not only internet and software skills but also strategies to give tests online, help with course design, and pedagogical resources for online teaching. In the University of North Carolina case, faculty training was supplemented with a support group to discuss and address effective use and monitoring of discussion forums and time management skills for emails, copyright and privacy issues, and ways to develop students' internet skills.

The faculty role has been changing from a sole lecturer of knowledge to a curator and facilitator of knowledge for some time (Godschalk \& Lacey, 2001). Online learning offers an opportunity to reach more students and a more diverse population of students (see also Lawhon, 2003). However, online learning must be accompanied by course design, technical support, and instructor training (Lawhon, 2003). Issues to plan for in online courses include how best to present the content of course lectures, how to build community and 
collaboration amongst students, and the remote library and technology services that are available to support students (Godschalk \& Lacey, 2001).

Challenges in retaining online learners in higher education have included student feelings of isolation, student difficulty in being self-directed, and overall lack of experience of students and faculty with online education (Holder, 2007). A study that asked students to rate in-class versus online discussion found that the online discussions were a useful supplement to the course; however, students preferred the in-class discussions based on sincerity, legitimacy, and comprehensibility (Willson, 2000). Typically, students that thrive and persist in online education include those that are academically prepared, engaged, self-directed, have computer skills, discipline, and time management skills (Holder, 2007). Persistent online learners were found to have emotional support, believe in their abilities, and have time management skills (Holder, 2007).

\section{Cultural Competency and Transformative Pedagogy}

There have been many efforts to diversify planning curricula, planning schools themselves, and the field of urban planning practitioners (Agyeman \& Erickson, 2012). There have also been efforts to reconcile differences, diversity, and heterogeneity within urban planning. Now that there is more physical distance between people without in-person events and with public mixing extremely limited, we must understand that technology use in urban planning is a cultural competency in itself as well as a tool (Agyeman \& Erickson, 2012). Data available online does not equally reflect all communities.

Cultural competency includes knowledge and skills to effectively engage in diverse environments. Proficiency in cultural competency demands flexibility and agility, especially in times when planners are removed from direct observation, ethnography, and action research to understand place-based attributes and community needs. Understanding differences and cultural needs to improve disparity is especially challenging when limited to only online data, especially when that data does not reflect certain communities such as migrants or informal economic sectors (Agyeman \& Erickson, 2012). Similarly, transformative pedagogy is an approach that encourages students to examine their assumptions, promotes student engagement while investigating social inequalities and posing actionable solutions (Meyers, 2008). This requires effort to create a safe environment for discussion on issues that may be personal to the students (Meyers, 2008). In online courses, this must be done through discussion boards or video conferencing. However, there is a digital divide between those with computer skills and internet availability, and those without (Cummins, 2000).

For accreditation of an urban planning higher education program, the American Institute of Certified Planners requires that a program attracts and retains a diverse stu- dent population. In particular, the program must attract and retain a diverse faculty population informed by the characteristics of the served population. Furthermore, professional ethics and values in the curriculum, including equity, diversity, and social justice, are a major component of the accreditation application (PAB, 2017).

A study of 695 research publications on distance learning found that access, equity, and ethics was the seventh most published topic followed by articles on globalization and cross-cultural aspects, as the 11th most published topic (Zawacki-Richter et al., 2009). A study of one hundred syllabi from seventy instructors found that a range of educational goals related to diversity and social justice existed in urban planning education in the United States (Sen et al., 2017). A key point in the study notes service learning as a powerful tool to expose students to different lived experiences, increase awareness of marginalized communities and facilitates, thinking about power relationships, and encouraging tailored approaches in urban planning solutions (Sen et al., 2017). These advantages of service learning depend on ethnography, fieldwork, and collaboration with a community partner or population. However, learning online inserts distance between the student or researcher and the site challenge (Shepherd \& Cosgrif, 1998).

Working in contexts of informal development or areas composed of migrant populations is challenging because they are often left out of digital data sets. Internet availability and access are two of the main challenges in low-income and economically developing contexts (Falco et al., 2019). While mapping tools and data are progressing across the world, there are exceptions where there are fewer applications in informal settings due to illegality or illegitimate business and informal housing, lack of education and information, as well as a lack of social and financial resources (Falco et al., 2019). Online tools offer greater participation in urban planning projects, for a more bottom-up process. However, it depends on internet infrastructure provision and training the community on how to use online participation tools (Deakin \& Allwinkle, 2007). There has been some progress made using drones or mobile phones including teaching residents to use online mapping tools to map their own neighborhoods in Caracas, Venezuela (Falco et al., 2019). This represents a data gap for researching project areas in an online urban planning program.

\section{Methods}

A database of 176 higher education programs was created from an internet search using the search terms online urban regeneration programs, online urban planning programs, online urban regeneration education programs, and online urban planning education programs. The Google search engine was used rather than a search engine like Duck Duck Go because Google provided more on-topic results from personalized search results. The first one hundred results of each search phrase were 
used. The search result relevance eventually degraded. Thirty-three bachelor or undergraduate degrees were found, seven certificate programs, six diploma programs, 108 postgraduate or master programs, and $22 \mathrm{PhD}$ or other doctorate program websites were found. These results were compiled into a database and reviewed for their degree level offering, their geographic location, the department or college discipline they are housed in, and their subfield within planning and urban regeneration.

Excluded from the analysis were unverifiable programs with little evidence online, including Bircham International University, which had several online degree programs in urban planning and design. One-off classes online via Coursera, FuturLearn, Massachusetts Institute of Technology (MIT) OpenCourseWare, or other online providers were also excluded. Webinars, discrete or short courses outside of a degree, were excluded. While educationally valuable to a wide variety of people especially in reach or spreading awareness of urban planning, these short courses or layperson offerings seemed marketed to a different audience than the degree programs, and it was unclear how to understand their academic impact or involvement. From this database, online urban planning programs were identified. These are planning programs in higher education that are offered, organized, and were created intentionally to be delivered online irrespective of Covid-19.

From the identified online programs in urban planning, a qualitative case study analysis was performed on the program curriculum. The program curriculum was scanned for class offerings in project-based learning, technical computer skills, and ethics in planning. A case study of experiences teaching during the transition from in-person to online learning is also offered. Case study research offers a detailed and nuanced examination of a particular case and is useful for understanding processes and connections (Mukhija, 2010). Case studies offer depth, richness, and particularity rather than generalization (Mukhija, 2010). Case studies and comparative approaches are qualitative research methods that extract substantial detail from the cases (Lauria \& Wagner, 2006). Multiple case studies increase the validity of observations and lead to generalization, but they also offer points of contrast to extrude more detailed observations (Mukhija, 2010). Qualitative methods are a reasonable starting point for a discussion on the quality of online urban planning programs.

\section{Mapping Online Urban Planning Programs}

Of the 176 program websites identified, 117 higher education programs were found in the United States and 34 were found in the United Kingdom. From Australia and New Zealand, six programs were found, six from Canada, 12 from countries in the European Union, and one from Tokyo, Japan. Of the states in the United States, California had the highest prevalence of urban planning courses in this study, with 18 programs found. Internationally, only the United Kingdom had more geographically, with 34 results, due to a combination of Wales, England, Scotland, and Northern Ireland universities. University College London (UCL) had the largest number of planning programs from a single university included in this study, with 13 results. Cardiff University had results for 10 planning programs. The colleges or faculties that the urban planning and regeneration programs were housed in were diverse, with many programs held within their own urban studies and planning schools, architecture and design schools, or public policy schools.

This study developed predominantly upon cases in the United States largely due to the availability of data. There is an English language bias in the search terms that makes a geographic analysis of urban planning and urban regeneration programs partially specious. The analysis of the locations where the programs were found provides a geographic view of the state of urban planning higher education and a body of data for further analysis in the United States.

Further parsing of the 117 United States programs identified 38 programs within colleges or schools with architecture, design, environmental design, or built environment in their names, possibly suggesting an atmosphere and pedagogical approach towards physical planning and built projects. Less common was for urban planning programs to have public service, public policy, or public health in their host college or school names with only 10 results. The University of Illinois at Chicago (UIC) has its own College of Urban Planning and Policy. Four programs were identified at UIC including urban studies, city design, and two programs in urban planning and policy. Trends of urban planning programs within home colleges for the international case collection were limited and dominated by UCL's 13 results, with the School of Planning located within the Faculty of the Built Environment and Cardiff's 10 planning programs being located within the School of Geography and Planning. A search was performed to identify online programs in urban planning. The results of the online urban planning programs are shown in Table 1.

Only eight online programs in urban planning were found during this search. They are all located in the United States. The resulting sample is a diverse set of community planning, design, and infrastructure online programs. The western United States, including Arizona, California, and Washington states, hold the majority of online programs.

\section{Case Studies in Online Urban Planning Education}

The University of Florida currently has the only accredited online urban planning program in the United States. The online Master of Urban and Regional Planning (MURP) and is similar to the accredited in-person program. The website states that the program was developed for working professionals. The online planning program is located within the College of Design, 
Table 1. Online urban planning and urban regeneration programs in higher education.

\begin{tabular}{lll}
\hline Degree or qualification & University & Title and discipline(s) \\
\hline Bachelor of Science & Arizona State University Online & Urban planning \\
Graduate certificate & Fresno State University & Community and regional planning \\
Graduate certificate & Northern Arizona University & Community planning \\
Graduate certificate & University of Florida & GIS for urban and regional planners \\
$\begin{array}{l}\text { Master of Infrastructure Planning } \\
\text { and Management }\end{array}$ & University of Washington & Infrastructure, planning, and management \\
$\begin{array}{l}\text { Master of Urban and Regional } \\
\text { Planning }\end{array}$ & University of Florida & Urban and regional planning \\
Executive Master of Urban Planning & University of Southern California & Urban planning \\
Master of Professional Science & Unity College & Urban ecology and sustainable development \\
\hline
\end{tabular}

Note: Entry requirements for Fresno State's program are unclear but it appears a student must be simultaneously enrolled in a graduate degree program or have achieved a graduate degree.

Construction, and Planning that hosts programs in architecture, construction management, interior design, historic preservation, landscape architecture, and sustainability. The college has both undergraduate and graduate programs, as well as a PhD program. There are three graduate online courses and one online undergraduate course along with the accredited online MURP program. There is also the Graduate Certificate in Geographic Information Systems for Urban and Regional Planners. The college offers study abroad programs in another distance learning strategy. This robust environment provides an opportunity for overlapping support for the online MURP. Curricular, staff, and technical resources can be shared, and help may be found from the inperson urban planning programs or other online programs. The online program requires 52 credit hours from a choice of 22 urban planning courses. Three units of the core requirements and 18 credits of the elective offerings qualify for the online GIS certificate, making it possible to achieve both the certificate and the accredited online MURP. Three credit hours of 34 are required in planning administration and ethics. One three-credit-hour elective course is offered in sustainable community development. The University of Florida online program is heavily weighted towards GIS, visualization, and information systems in planning. The online program does not exactly mirror the in-person program.

There is less breadth of education in the online program versus the in-person program. In the online program, eighteen of the thirty elective choices are geared towards GIS and computer skills. The electives for the online MURP program offer courses not included in the in-person MURP plan of study including a course on sustainable urban development and four courses in information systems and visualization that overlap with offerings from the online GIS certificate for planners. In short, the online MURP program appears to have lost some breadth from the in-person MURP course, including those that may educate planners in social and community issues. The online MURP program relies on the GIS and computer systems courses that overlap with the GIS graduate certificate program.

The University of Southern California (USC) Executive Master of Urban Planning is geared towards mid-career professionals and focuses on urban planning and real estate development. The program is approximately 16 months based on 10 courses, comprising 24 units of coursework. The courses are live online and there are two in-person intensive sessions. The program is focused on politics, collaboration, and building development processes. Key components of the USC program are two intensive in-person sessions with the executive cohort. There is one in-person session per year, allowing for socialization and collaborative work, and may even support social networks during the online portions of the course. These two intensive courses are four days each year of the program and focus on immersive urban planning projects, providing the missing site work and real-world problem-solving work that is difficult to achieve in online urban planning courses. Students collaborate and consider real-world ethical issues and stakeholders of the project place.

Unity College offers a master's in urban ecology and sustainable planning. Unity College has seven online graduate programs and two online certificates predominantly in environmental subjects. The program in urban ecology and planning features personal one-on-one academic advisement. Fieldwork is required at the student's location as part of the course. Similar to the University of Florida and the USC programs, the program allows flexibility for working professionals. The program is organized around a foundation of sustainability and skills courses for the core required courses. A course in ethical practice is required as part of the skills core classes. It is possible to complete the course in twelve months and there are five start dates per year. 
The University of Washington holds an online Master of Infrastructure Planning and Management degree. The program is asynchronous, with students taking their courses in the form of podcasts and videos. Courses are organized into core courses, methods courses, and systems courses including infrastructure, food, and public health. The program also requires two capstone courses focused on a real-world problem. The program provides a breadth approach to education in the environment, social equity, and methods or skills.

Arizona State University offers the only undergraduate degree found in this study. The curriculum is entirely online, including undergraduate breadth requirements such as writing composition and mathematics courses typical of undergraduate education in the United States. The urban planning curriculum is slim, composed of an introductory urban planning course, some GIS courses, and some electives. However, this program shows a multi-year and multi-disciplinary undergraduate education can be delivered online.

Northern Arizona University offers an online graduate certificate in community planning. Student learning outcomes focus on analysis, professional development, and geospatial technology. The program requires 12 course units of approximately five courses. The University of Florida provides an online GIS certificate for planners. The program requires three core courses and one elective for 12 credit hours total of approximately 12-15 months. California State University, Fresno, has a Community and Regional Planning Certificate of Advanced Study composed of five required courses that cover a breadth of introductory urban planning topics including community planning, transportation planning, and land use regulation. GIS, technical, and professional skills are absent from this compact online curriculum.

\section{Transitioning From In-Person to Online Urban Planning Education at Cal Poly Pomona}

After transitioning from in-person to online teaching in the Department of Urban and Regional Planning at Cal Poly Pomona, we have used Zoom, an online video conferencing software provided by Cal Poly Pomona to faculty and students, predominantly for lectures, class meetings, department events, and office hours. I have used the screen sharing feature to demonstrate software online, including AutoCAD and Adobe Illustrator. Students "screen-share" to present their work, usually composed of designs and diagrams, in PDF format. The College of Environmental Design has also made use of Conceptboard, a collaborative online whiteboard software. I have used Conceptboard for classes similar to the way an in-person urban planning workshop might make use of a large sheet of paper where everyone can mark up and add images at the same time to a communal board.

During the summer of 2020, the university provided stipends for classes in online teaching. The Center for the Advancement of Faculty Excellence has provided various resources from webinars to technical support, and source material to support faculty and course design. Students were also provided laptops on loan and software, including the Adobe Creative Suite, which the university provided for free. However, the campus closure disconnected students from essential services. Homeless or housing insecure students depend on the library for study and internet access, the gym for showers, and the food pantry for groceries.

The transition from in-person to online teaching was smoother for lecture courses that could be lectured through Zoom as they were in person. Some lecturers and professors chose to record their lectures so that students could review lectures in their own time. We had three options for course offerings, synchronous over Zoom where the course would meet, similar to an in-person class but online, asynchronous where professors would prerecord lectures or plan activities for students to do in their own time and a third, hybrid approach, with some combination of live online meetings, and some exercises or lectures for students to complete asynchronously.

After initial learning curves, faculty sensed that lectures and analysis courses translated sufficiently online, with many online resources available including Google Maps, Google Earth, and census data for analysis work. The United States provides census data online and, while this is flawed, it is a substantial starting point for educating students on social and spatial issues. California also requires cities to provide land use or zoning maps online, sometimes in the form of a GIS portal, an online tool like Los Angeles City's ZIMAS, or sometimes a PDF map. We were prevented from on-campus or off-campus class meetings, including site visits for class project sites, but Google Street View and other online images partially filled this visual gap. Some efforts at social learning included the use of break-out rooms on Zoom for project groups to work together. The students used the Discord instant messaging communication software on their own for projects, text communication, and sharing media files. I found that socialization must be built through time set aside during class for social activities.

Redesigning urban design studio courses at Cal Poly Pomona required strategizing ways to acquire data, especially to supplement the lack of site visits. Google Street View and searching for photos online was problematic in that the images may be outdated. The Google Street View perspective was also slightly warped and not completely accurate in dimensions.

However, it remains unclear how much was lost through in-person learning in terms of spontaneous or serendipitous learning, and social learning from peers. Urban design project work was particularly different between in-person and online models especially with the prohibition of site visits. Site visits allow for panoramic sensory input well beyond what online images can provide. Things like temperatures cannot be simultaneously 
felt in combination with other site attributes such as dust, lack of shade, wind, noise from cars, etc. Showing students how to draw required some awkward camera positioning or holding up of drawn examples. Since site visits were prohibited, I chose sites for the urban design studios that were either further away, including the Salton Sea, which is approximately 136 miles away from Cal Poly Pomona, or normally prohibitive for health and safety reasons including Skid Row in Downtown Los Angeles. I took Covid-19 site visit prohibitions as an opportunity to provide sites for students that we normally wouldn't be able to study in person anyway. Student feedback included an appreciation for working in disadvantaged communities like Skid Row, an intense concentration of the unhoused population of Los Angeles, and a low-population agricultural area that usually does not receive a lot of planning attention like Mecca, near the Salton Sea.

For a lecture course in international planning, I livelectured half the course, and students worked asynchronously on individual weblogs (blogs) where they reviewed academic articles and online news reports. This prompted students to do their readings and write about them, and had a few added benefits, including a design element for their blog templates and the images they chose. I hoped the blogs would also be a social activity with students viewing and commenting on each other's posts, but this did not come to fruition. Students said they always wanted to create a blog but never had the added motivation. Students also have practiced internet skills and they can host their own portfolios where they can direct future employers.

Fundamental discrepancies or inequality in remote or online education identified while at Cal Poly Pomona this past year during the coronavirus pandemic include many financial and service hurdles for students to overcome. Some students do not have reliable internet or must attend class online via their mobile phones. Many students have suffered job losses due to Covid-19 and subsequently have taken new jobs, even some that were in high-risk situations for contagion including jobs as caretakers or jobs in grocery stores. Students' housing situations changed largely, with many giving up their apartments and moving back to their family homes. This is often a distracting experience due to noisy environments or people nearby within crowded living situations.

\section{Conclusion}

Covid-19 pushed educators to innovate rapidly to deliver education in urban planning online. Fortunately, there were many online tools available including online video conference platforms like Zoom and Microsoft Teams. These were underutilized in many ways before Covid-19 and we have found that online video conferencing works well for meetings and lectures, without requiring the time and energy for travel. Unfortunately, the fact that there are only eight higher education program degrees online in urban planning disciplines suggests that there is little experience in the field of online learning and remote teaching. This suggests there may be an insufficient market for those interested in online urban planning education.

From a qualitative case study analysis of online programs in urban planning in the United States, several different approaches to the curriculum were discovered. The University of Florida MURP cases show that online programs can achieve accreditation and provide most of the curriculum that an in-person course provides. The Florida case also shows that GIS and computer visualization courses may more easily and more naturally be provided online than community development or social justice courses due to the computer-oriented nature of the work. However, with online learning creating more distance between students and their site communities, more effort must be made to offer social learning, ethnographic site analysis, and collaborative classes than inperson courses to serve site communities beneficially.

The USC Executive Master of Urban Planning is a much shorter curriculum than the University of Florida MURP. The USC program focuses on community engagement and building development, presenting a contrast to the University of Florida case. The USC program eschews a breadth curriculum of planning and only includes one obvious computer data analysis course titled Big Data for Planning and Development. This executive program could be expanded to an MURP program like the University of Florida program by expanding course offerings in urban planning foundations and computer skills. The University of Florida program could incorporate more of the USC-style politics and engagement courses into its curriculum. The USC program includes two in-person intensives that partially bridge the gap between the disadvantages of online learning by providing face-to-face time for students to get to know each other, work together, make real-life social connections, and buoy social support during online learning. These in-person intensive courses also offer students potential experience in workshops and other in-person planning methods as well as the opportunity to gain collaborative project site and community interaction experience.

Other measures that mitigate the loss of social or collaborative learning and in-person site work include Unity College's requirement that their students perform fieldwork, USC's live online course delivery rather than just video or podcast lectures, and Unity College's provision of personal one-on-one academic and professional advisement. Tuition estimates for six of the eight programs were higher for online programs by per-unit costs than in-person programs excepting Arizona State University and Unity College. Some costs are saved for students in online education because they can live wherever the cost of living is more convenient to them, comparatively less expensive, but it is unclear why online education would be more expensive in tuition considering there are savings for the university, including reduced 
costs of classrooms, heating, cooling, and other overhead expenditures.

Craig Calhoun states that relationships made through technology foster simplistic or categorical, topic-based, identities and relationships, rather than the multiple and systemic relationships forged in physical life (Calhoun, 1998). Calhoun wrote that the internet matters more as a supplement to face-to-face community and that it doesn't necessarily allow for new things but for doing things that we were already doing or wanted to do more efficiently. Calhoun states that the internet is a most useful tool when building on the capacity of physical life rather than attempting a substitute for it (Calhoun, 1998). Online learning does not provide the serendipitous or social learning inherent in in-person classes. Socialization and collaboration must be formally included and designed into classes through activities or exercises.

Salama (2020) notes that there are ethical considerations in a world less bounded by physical space and with online connections strengthened. In an online learning environment, students must have equal access and provision to the internet and technology for the benefits of dispersed planning education to materialize. Traditionally, distance learning opened up education to more diverse student bodies, including older and working students (Godschalk \& Lacey, 2001; Holder, 2007). The current wave of online learning may further open education to working students, students that live far from their university, and possibly a greater economically diverse student population because it takes money to move homes and change jobs to be near the university. However, the Cal Poly Pomona case shows that this beneficial potential for more learners has to be balanced with the knowledge that the internet, mobile technology, and up-to-date computers for online learning include an economic cost for students.

\section{Acknowledgments}

The author thanks the other faculty members of the Department of Urban and Regional Planning at California State Polytechnic University Pomona, especially Professor Rick Willson, for our ongoing discussions on teaching and learning. The author also thanks the reviewers for their time and constructive comments.

\section{Conflict of Interests}

The author declares no conflict of interests.

\section{References}

Agyeman, J., \& Erickson, J. S. (2012). Culture, recognition, and the negotiation of difference. Journal of Planning Education and Research, 32(3), 358-366. https://doi. org/10.1177/0739456X12441213

Alpopi, C., \& Manole, C. (2013). Integrated urban
regeneration-Solution for cities revitalize. Procedia Economics and Finance, 6, 178-185. https://doi.org/ 10.1016/S2212-5671(13)00130-5

Batty, M., \& Marshall, S. (2017). Thinking organic, acting civic: The paradox of planning for cities in evolution. Landscape and Urban Planning, 166, 4-14. https:// doi.org/10.1016/j.landurbplan.2016.06.002

Calhoun, C. (1998). Community without propinquity revisited: Communications technology and the transformation of the urban public sphere. Sociological Inquiry, 68(3), 373-397. https://doi.org/10.1111/ j.1475-682X.1998.tb00474.x

Cummins, J. (2000). Academic language learning, transformative pedagogy, and information technology: Towards a critical balance. TESOL Quarterly, 34(3), 537-548. https://doi.org/10.2307/3587742

Dalton, L. C. (1989). Emerging knowledge about planning practice. Journal of Planning Education and Research, 9(1), 29-44. https://doi.org/10.1177/ $0739456 \times 8900900103$

Dalton, L. C. (2001). Weaving the fabric of planning as education. Journal of Planning Education and Research, 20(4), 423-436. https://doi.org/10.1177/ $0739456 \times 0102000404$

Deakin, M., \& Allwinkle, S. (2007). Urban regeneration and sustainable communities: The role of networks, innovation, and creativity in building successful partnerships. The Journal of Urban Technology, 14(1), 77-91. https://doi.org/10.1080/10630730701 260118

Falco, E., Zambrano-Verratti, J., \& Kleinhans, R. (2019). Web-based participatory mapping in informal settlements: The slums of Caracas, Venezuela. Habitat International, 94. https://doi.org/10.1016/ j.habitatint.2019.102038

Freestone, R. (2012). Futures thinking in planning education and research. The Journal for Education in the Built Environment, 7(1), 8-38. https://doi.org/ 10.11120/jebe.2012.07010008

Godschalk, D. R., \& Lacey, L. (2001). Learning at a distance. Journal of Planning Education and Research, 20(4), 476-489. https://doi.org/10.1177/0739456X 0102000411

Hall, P. (1998). Cities in civilization. Pantheon Books.

Hall, P. (2007). Melvin M. Webber: Maker and breaker of planning paradigms. Access Magazine, 2007. https:// www.accessmagazine.org/special-issue/melvin-mwebber-maker-and-breaker-of-planning-paradigms

Holder, B. (2007). An investigation of hope, academics, environment, and motivation as predictors of persistence in higher education online programs. The Internet and Higher Education, 10(4), 245-260. https:// doi.org/10.1016/j.iheduc.2007.08.002

Jacobs, J. (1961). The death and life of great American cities. Random House.

Lauria, M., \& Wagner, J. A. (2006). What can we learn from empirical studies of planning theory? A comparative case analysis of extant literature. Journal 
of Planning Education and Research, 25(4), 364-381. https://doi.org/10.1177/0739456X05282351

Lawhon, L. L. (2003). Do distance learning efforts in urban planning education cut short the educational experience? Journal of Planning Education and Research, 23(2), 202-205. https://doi.org/10.1177/ 0739456X03258949

Meyers, S. A. (2008). Using transformative pedagogy when teaching online. College Teaching, 56(4), 219-224. https://doi.org/10.3200/CTCH.56.4.219224

Moore, S., Rydin, Y., \& Garcia, B. (2015). Sustainable city education: The pedagogical challenge of mobile knowledge and situated learning. Area, 47(2), 141-149. https://doi.org/10.1111/area.12127

Mukhija, V. (2010). N of one plus some: An alternative strategy for conducting single case research. Journal of Planning Education and Research, 29(4), 416-426. https://doi.org/10.1177/0739456X10362770

Myers, D., \& Kitsuse, A. (2000). Constructing the future in planning: A survey of theories and tools. Journal of Planning Education and Research, 19(3), 221-231. https://doi.org/10.1177/0739456X0001900301

PAB. (2017). PAB accreditation standards and criteria.

Pain, K. (2016). The strategic planning protagonist: Unveiling the global mega-city Regio. In R. D. Knowles \& C. Rozenblat (Eds.), Sir Peter Hall: Pioneer in regional planning, transport and urban geography (pp. 59-80). Springer.

Reades, J. (2016). Location and innovation. In R. D. Knowles \& C. Rozenblat (Eds.), Sir Peter Hall: Pioneer in regional planning, transport and urban geography (pp. 21-35). Springer.

Ryan, P. (2021, April 20). US office market statistics, trends \& outlook. JLL. https://www.us.jll.com/en/ trends-and-insights/research/office-marketstatistics-trends

Salama, A. M. (2008). A theory for integrating knowledge in architectural design education. International Journal of Architectural Research, 2(1), 100-128.

Salama, A. M. (2020). Coronavirus questions that will not go away: Interrogating urban and socio-spatial implications of COVID-19 measures. Emerald Open Research, 2, Article 14. https://doi.org/10.35241/ emeraldopenres.13561.1

Sen, S., Umemoto, K., Koh, A., \& Zambonelli, V. (2017). Diversity and social justice in planning education: A synthesis of topics, pedagogical approaches, and educational goals in planning syllabi. Journal of Planning Education and Research, 37(3), 347-358. https://doi.org/10.1177/0739456X16657393

Shepherd, A., \& Cosgrif, B. (1998). Problem-based learning: A bridge between planning education and planning practice. Journal of Planning Education and Research, 17(4), 348-357. https://doi.org/10.1177/ 0739456X9801700409

Shifting some employees to remote work permanently. (2020, April 3). Gartner. https://www.gartner.com/ en/newsroom/press-releases/2020-04-03-gartnercfo-surey-reveals-74-percent-of-organizationsto-shift-some-employees-to-remote-workpermanently2

Teitz, M. (2007). Melvin Webber and the "nonplace urban realm." Access Magazine, 2007. https://www. accessmagazine.org/special-issue/melvin-webberand-the-nonplace-urban-realm

Willson, R. (2000). Comparing in-class and computermediated discussion using a communicative action framework. Journal of Planning Education and Research, 19(4), 409-418. https://doi.org/10.1177/ 0739456X0001900410

Yin, L. (2010). Integrating 3D visualization and GIS in planning education. Journal of Geography in Higher Education, 34(3), 419-438. https://doi.org/10.1080/ 03098260903556030

Zawacki-Richter, O., Baecker, E. M., \& Vogt, S. (2009). Review of distance education research (2000 to 2008): Analysis of research areas, methods, and authorship patterns. The International Review of Research in Open and Distributed Learning, 10(6), 21-50. https://doi.org/10.19173/irrodl.v10i6.741

\section{About the Author}

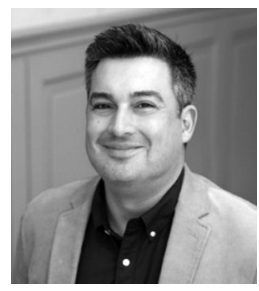

Brian Garcia (PhD) is assistant professor in urban and regional planning at the California State Polytechnic University Pomona. Brian teaches urban design, housing, and international planning. His research is focused on sustainable housing and transport. Brian has practiced internationally in architecture and urban design. 